\title{
Surface-active Properties of Extracted Saponin from the Leaves of Nephelium Lappaceum.
}

\author{
N. J. Janurin ${ }^{1}$, A.N. Mohamed ${ }^{1, *}$ and Y.A. Che Yahaya ${ }^{1}$ \\ ${ }^{1}$ Faculty of Industrial Sciences and Technology, Universiti Malaysia Pahang, 26300 Gambang, Pahang, Malaysia.
}

\begin{abstract}
Synthetic surfactants are widely used in a wide array of cleaning products due to their ability in lowering the surface tension of water. These surfactants also come with bad effects on people's health and the environment. Plant-based surfactant, or saponin, is expected to produce the same desired effect of chemical surfactant, minus the negative effect. The purpose of the current research was to discover the surface-active properties of saponin extracted from Nephelium Lappaceum or rambutan leaves, relative to commercial surfactant, Tween 80 , and SDS. Rambutan's leaves were extracted by maceration technique and liquid-liquid extraction to remove proteins and lipids of the plant. The presence of saponin in crude rambutan leaves was verified by foam test, which showed positive results. The crude rambutan leaves extracts were further analyzed by FTIR, GC-MS, and LC-QTOF-MS. The surface-active test consisted of a wetting test and cleaning test. The results from the IR spectrum show the presence of functional groups of saponin; $\mathrm{OH}, \mathrm{C}=\mathrm{O}, \mathrm{C}-\mathrm{H}, \mathrm{C}=\mathrm{C}$, then, $\mathrm{C}-\mathrm{O}$ which indicates the glycosides linkages to sapogenins. The wetting time for leave extracts, SDS, and Tween 80 were $32.33 \mathrm{~s}, 7.33 \mathrm{~s}$, and $17.62 \mathrm{~s}$ respectively. The cleaning test of saponin fraction, SDS, and Tween 80 showed the percentage of $20.98,80.40$, and 37.3 respectively. Generally, Rambutan leaves extract showed promising, but lower surface activities compared to commercial surfactants. Considering that the saponin fraction was not yet in the purest or isolated form of a single compound, it can be said the potential can be further enhanced by further isolating a pure surface-active compound from the saponin fraction.
\end{abstract}

\section{ARTICLE HISTORY}

Received: $24^{\text {th }}$ June 2020

Revised: $7^{\text {th }}$ January 2021

Accepted: $11^{\text {th }}$ Mar 2021

\section{KEYWORDS}

Surfactant,

Saponin,

Surface active

\section{INTRODUCTION}

Surfactants are the most versatile products of the chemical industry. There are utilized in every industrial area ranging from household detergents to drilling muds and food items to pharmaceuticals. They find application in several end-use industries such as petroleum, pharmaceuticals, agrochemicals, and cosmetics. The home care product is the most used surfactant in their product. Based on the current recorded Malaysian population of 29.91 million people the calculated market size for laundry detergents is 110,000 metric tonnes [15]. The anionic surfactant is the most surfactant used in industries. Most anionic surfactants are produced from chemical substances [5]. It gives a bad effect on human health and the environment. One of the alternatives ways is to make an organic soap or laundry detergent that make from a natural plant compound which is saponins $[2,4,8]$. Saponins are usually found in the plant which has a foaming characteristic. The surfactants obtained directly from natural sources such as plants or animals are regarded as natural surfactants. Saponins are a diverse group of compounds widely distributed in the kingdom of plants [3], characterized by a triterpene or steroid aglycone structure and one or more sugar chains [1]. It can react as a cleansing agent with its foaming and wetting properties and more important is not harmful to human health and the environment due to its ingredients which are not mixed with chemical substances [9]. Most saponins are found in vegetables, beans, and herbs such as soybeans, peas, and some herbs named Soapwart (Sapponaria Officinalis, Caryophyllaceae) [8]. One of the plants that can be commercialized as a surfactant is rambutan leaves because it was easy to find in Malaysia [14, 16]. The idea that Rambutan leaves contain saponin comes from the fact that the leaves will produce foam if macerated in water. Saponins are a diverse group of compounds that are containing one or more triterpene or steroid aglycone sugar chains and are widely distributed in the plant kingdom [6]. Saponin also can react as a surfactant due to the presence of amphiphilic nature which is a lipidsoluble chain of aglycone and water-soluble sugar chain. Since their excellent functional properties, health benefits, and environmental protection, plant-derived saponins have gained increased interest. These are less toxic, more biodegradable, and more reusable than other forms of surfactants [11,12]. Surface-active properties of saponin extracted from Rambutan leaves were investigated through wetting, foam formation, and cleaning test. The properties were also compared with synthetic and commercial surfactants; Sodium Dodecyl Sulfate (SDS) and Tween 80. 


\section{MATERIALS AND METHODS}

\section{Preparation of Plant Extraction}

The maceration extraction method was used. The rambutan leaves were soaked with ethanol in a beaker. The beaker was covered with aluminum foil and left for 3 days at room temperature. After that, the mixture was strained by filtration.

\section{Saponin extraction}

About $200 \mathrm{ml}$ of leave sample and ethanol mixture was dissolved in $50 \mathrm{ml}$ ethanol and $200 \mathrm{~mL}$ chloroform was added in a separatory funnel. The extracted ethanol was collected from the separation and petroleum ether was added about 200 $\mathrm{ml}$ in the separatory funnel. The ethanol fraction was filtered by vacuum filtration. Ethanol was removed using a rotary evaporator. Then, the extracts were transferred to a water bath for water removal. The water bath was set at $70{ }^{\circ} \mathrm{C}$ and left for $24 \mathrm{hr}$. Finally, extracted saponin was collected and stored in a beaker covered with aluminum foil and stored in the refrigerator at a temperature of $4^{\circ} \mathrm{C}$.

\section{Froth Test}

The presence of extracted saponin was detected by shaking vigorously the test tubes containing the saponin extracted and tap water, for about a minute. The height of the foam generated was measured immediately and after 5 minutes. Persist foaming, minimum $1 \mathrm{~cm}$, even after 5 minutes indicates the presence of saponin.

\section{FTIR analysis}

About $5 \mathrm{~g}$ of saponin extract was mixed with potassium bromide $(\mathrm{KBr})$ with a ratio of 1:10 by using mortar and pestle to make a fine powder. Then, it was compressed by a manual hydraulic press to a thin pellet. Finally, the pellet will be placed in the FTIR spectrophotometer for the examination process. The infrared absorption spectrum with a scan range from 400 to $4000 \mathrm{~cm}^{-1}$ was obtained from the analysis of the extracted saponin to identify the chemical bonds in the sample's molecule.

\section{Wetting Test}

The wetting test was conducted using canvas disc wetting sets. Firstly, a white cotton cloth $(5 \times 5) \mathrm{cm}$ was cut. Then, three solutions (Saponin extracts, SDS, and Tween 80) were prepared in a $250 \mathrm{~mL}$ beaker. $1 \mathrm{~g}$ of each sample was mixed with $99 \mathrm{~mL}$ of water. White cotton cloth was sunk into each solution in the beaker. The cloth floated on the top of the solution. The wetting time was determined by measuring the time needed to begin sinking the cloth [9]. The time required for the cloth to begin to sink was recorded three times per solution.

\section{Cleaning Test}

Three surfactant solutions which are Rambutan leaves extract solution, sodium dodecyl sulfate (SDS) solution, and Tween 80 solution, were used for the cleaning study. Nine $(5 \times 5) \mathrm{cm}$ of white cotton cloth were immersed in water for 24 $\mathrm{hr}$, dried, and weighed. Simulated dirt was prepared by mixed $1 \mathrm{~g}$ of oil and $1 \mathrm{~g}$ of paraffin wax in $100 \mathrm{~mL}$ hexane. For 10 minutes, the white cotton fabric was covered in simulated dirt. The fabric was then dried and reweighed. The clothes were also shaken in surfactant solution during this process. The cloth then was washed with water after it was taken out, dried, and reweighed. All the weights represented the percentage of cleaning were recorded and calculated by the formula below, where W1 is the initial weight of the cloth, W2 is the weight of the cloth with simulated dirt and W3 is the weight after being cleaned with surfactant solution and water.

$$
\mathrm{C}=[(\mathrm{W} 2-\mathrm{W} 3) /(\mathrm{W} 2-\mathrm{W} 1)] \times 100 \%
$$

\section{RESULTS AND DISCUSSION}

\section{Froth Test}

The persistence of soap-like foam for about 5 minutes indicated the presence of saponin in Rambutan leaves extract. Figure 1 shows the foam formation of the extracts which was measured to be about $1 \mathrm{~cm}$. Saponins with one sugar chain have the best foaming functionality while compounds with two or three sugar chains show a reduction in foaming capacity [10]. 


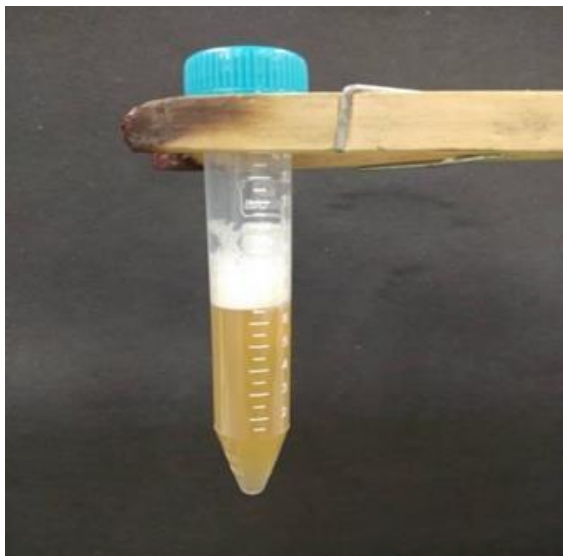

Figure 1. Persistent foam formation, about $1 \mathrm{~cm}$, after 5 minutes.

\section{FTIR analysis}

Figure 2 and Table 1 show FTIR spectrum and data of saponin extract. The result of the FTIR spectra of saponin demonstrated characteristics of functional group that plays the role as a saponin chemical structure were $\mathrm{OH}, \mathrm{C}=\mathrm{O}, \mathrm{C}-\mathrm{H}$, $\mathrm{C}=\mathrm{C}$, then, $\mathrm{C}-\mathrm{O}$ which indicates the glycosides linkages to sapogenins [1].

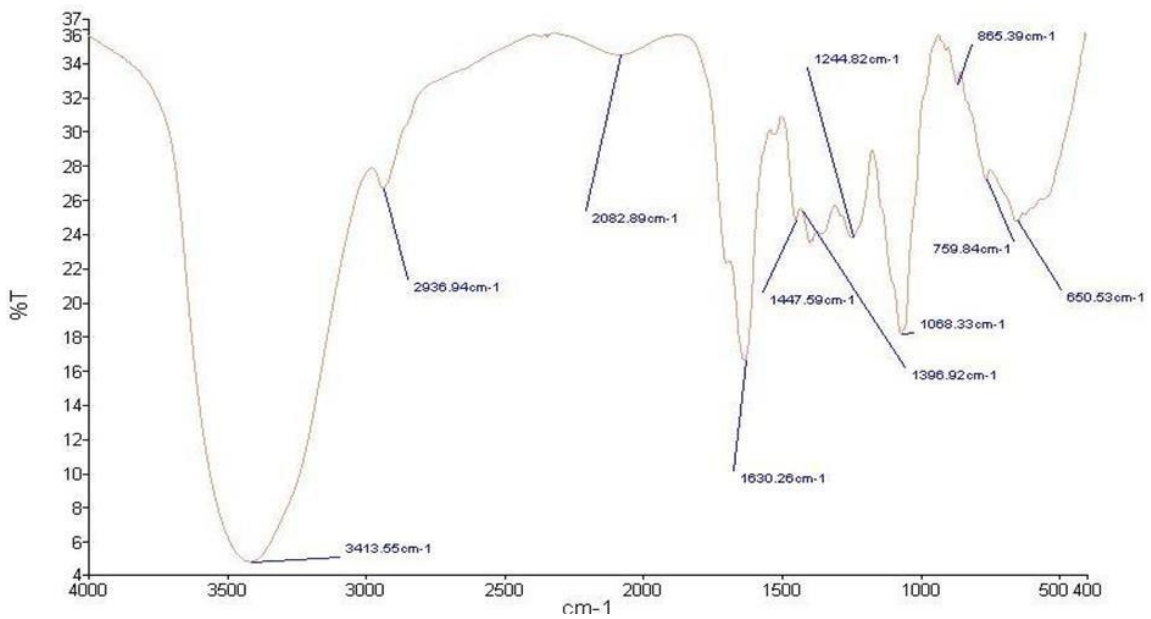

Figure 2. IR spectrum of saponin extracts.

Table 1. FTIR data of saponin extracts.

\begin{tabular}{lll}
$\begin{array}{l}\text { Functional } \\
\text { Group }\end{array}$ & $\begin{array}{l}\text { Wavenumber } \\
\left(\mathbf{c m}^{-\mathbf{1}}\right)\end{array}$ & Intensity \\
\hline O-H (alcohol) & 3413.55 & Strong, Broad \\
C-H (alkane) & 2936.94 & Medium \\
C=O & 1712.78 & Medium \\
C $=\mathrm{C}$ & 1630.36 & Strong \\
\hline
\end{tabular}




$\begin{array}{lcl}\text { C-H methyl } & 1447.59- & \text { Medium } \\ & 1396.92 & \\ \text { C-O (ether) } & 1068.33 & \text { Strong } \\ \text { =C-H } & 865.39 & \text { Medium } \\ & & \\ \text { =C-H and C-H } & 759.84 & \text { Medium }\end{array}$

Data of the IR spectrum shows absorption in the range from $650.53 \mathrm{~cm}^{-1}$ to $3413.55 \mathrm{~cm}^{-1}$. A strong and broad peak at $3413.55 \mathrm{~cm}^{-1}$ represents it has a hydroxyl group $(-\mathrm{OH})$ in extracted saponin fraction. The presence of a functional group of hydroxyl groups shows a broad and strong intensity with a stretch type of vibration. Then, carbon-hydrogen (C-H) absorption ranged from $2936.94 \mathrm{~cm}^{-1}$ which showed the functional group of alkanes. The intensity is medium with a stretch type of vibration. Furthermore, the $(\mathrm{C}=\mathrm{O})$ absorbance was found to be at $1712.78 \mathrm{~cm}^{-1}$ with medium intensity in the infrared spectrum. Besides that, the $(\mathrm{C}=\mathrm{C})$ absorbance was observed from the infrared spectrum with strong intensity at $1630.36 \mathrm{~cm}^{-1}$. Besides, the (C-H) methyl ranges from $1447.59 \mathrm{~cm}^{-1}$ to $1396.92 \mathrm{~cm}^{-1}$. It proved that there is bending and rocking vibration with medium intensity. Oligosaccharide linkage absorption to sapogenins, that is (C-O-C), was evident between $1068.33 \mathrm{~cm}^{-1}$ with medium intensity in saponin rambutan leaves extract fraction. Out of plane $\mathrm{CH}$ bending, there are $(=\mathrm{C}-\mathrm{H})$, alkenes absorbance from $865.39 \mathrm{~cm}^{-1}$ and $(=\mathrm{C}-\mathrm{H}),(\mathrm{C}-\mathrm{H})$ bond that can show the absorbance presence from $764.12 \mathrm{~cm}^{-1}$. This range of absorption may cause by the bending of alkene and overlapping of rocking vibration of methylene. Based on the previous research that identified the functional group that contained in Nephelium Lappaceum leaves show the result of the FTIR spectra of saponin demonstrated characteristic of functional group that plays the role as a saponin chemical structure were $\mathrm{OH}, \mathrm{C}=\mathrm{O}, \mathrm{C}-\mathrm{H}, \mathrm{C}=\mathrm{C}$, then, $\mathrm{C}-\mathrm{O}$ which indicates the glycosides linkages to sapogenin. Based on previous research of extraction saponin from soapnut, several functional groups of a functional group for saponin can be identified such as $-\mathrm{OH}$ alcohol, aliphatic $\mathrm{C}-\mathrm{H}$ groups, $\mathrm{C}=\mathrm{O}$ of carboxylic acid or ester, $\mathrm{C}=\mathrm{C}$ bonds, and bending of $-\mathrm{CH} 3 /-\mathrm{CH} 2-$ groups [12].

\section{Foaming Test.}

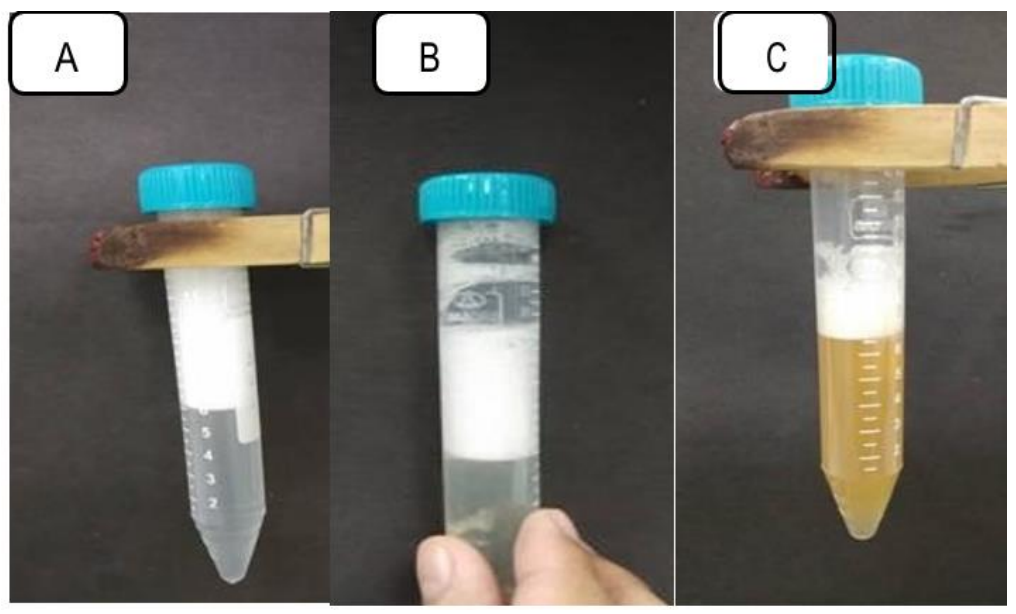

Figure 3. Foam level produced by A) SDS, B) Tween 80, C) Saponin extracts

Figure 3 shows foam formation of SDS, Tween 80, and saponin extracts. It can be observed that SDS showed the highest foam formation $(5 \mathrm{~cm})$, followed by Tween $80(3 \mathrm{~cm})$ and saponin extracts $(1.5 \mathrm{~cm})$. Considering that the extracts are not surfactant in their purest form, it can be said that the extracts showed promising foaming activity. 


\section{Wetting time.}

A wetting test was carried out to observethe ability of the liquid to maintain contact with a solid surface. Table 2 shows the wetting test data of SDS, Tween 80, and saponin extracts. The data shows that SDS had the fastest wetting time as the time recorded was $7.33 \mathrm{~s}$, followed by Tween 80 at $17.67 \mathrm{~s}$. Saponin fraction wetting time was $32.33 \mathrm{~s}$. During the testing procedure, white cotton cloth sinks to the bottom of the beaker containing saponin fraction, which indicates wetting properties and intermolecular structure between the white cotton cloth and water. The water was able to maintain contact with the white cotton cloth. Due to the ability to displace air weaker than SDS and Tween 80 from a liquid or solid saponin surface, cotton cloth in SDS and Tween 80 will take a shorter time for wetting than a cotton cloth in saponin. It clearly can be seen that the synthetic surfactant caused the greatest decrease in its surface tension to a minimal value. However, the saponin showed promising properties.

Table 2. Wetting time of SDS, Tween 80 , and saponin extracts

\begin{tabular}{lc}
\hline Surfactant & Wetting time \\
\hline SDS & $7.33 \pm 5$ \\
Tween 80 & $17.67 \pm 3$ \\
Saponin extract & $33.43 \pm 2$ \\
\hline
\end{tabular}

\section{Cleaning properties.}

Cleaning properties are the result of the amphiphilicity of surfactant which enhancing the reduction of surface and interfacial tensions [7]. The average percentage of cleaning can be seen in Figure 4. The cleaning properties of surfactants and saponin extract were identified by the percentage of cleaning. The weight of dirt white cotton cloth was measured after being cleaned by saponin extracts. The decrease in weight shows the effectiveness of the surfactant in cleaning. The decrease of weight for cloth after of cloth after submerged in dirt and washed by tap water shows the effectiveness of cleaning.

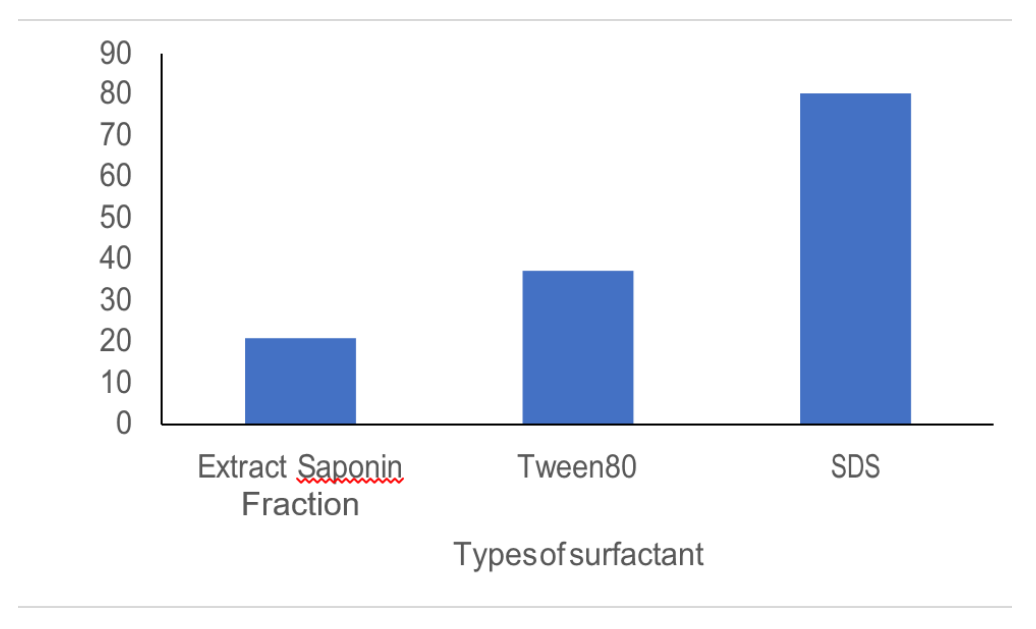

Figure 4. Cleaning properties of surfactant sample.

From Figure 4, the cleaning percentage of saponin extracts, Tween 80 and SDS is $20.98 \%, 37.33 \%$, and $80.40 \%$ respectively. SDS, being an anionic surfactant, works best to remove dirt, clay, and some oily stains. These surfactants work the following ionization. When added to water, the anionic surfactants ionize and have a negative charge. The negatively charged surfactants bind to positively charged particles like clay [17]. Sodium dodecyl sulfate forms relatively spherical micelles with hydrophobic tail groups oriented towards the center and charged head groups along the outer surface [13]. The surfaces of SDS micelles possess a large net negative charge, giving them large electrophoretic mobility toward the anode. In general, anionic surfactants tend to generate higher foam levels than other classes of surfactants [17]. 


\section{CONCLUSION}

This research shows promising surface-active properties of saponin extracted from Rambutan leaves. In relative to commercial and synthetic surfactants, the extracted saponin showed the lowest level of activity. Considering that the saponin was not in the form of purified surfactant yet, the activities can be predicted to go higher once the purification and isolation process is carried out.

\section{ACKNOWLEDGEMENT}

The author would like to thank Universiti Malaysia Pahang and Mygrants (FRGS/1/2019/WAB13/UMP/02/2) for funding this work.

\section{REFERENCES}

[1] Almutairi, M. S., \& Ali, M. (2015). Direct detection of saponins in crude extracts of soapnuts by FTIR. Natural Product Research, 29(13), 1271-1275.

[2] Chai, K. F., Adzahan, N. M., Karim, R., Rukayadi, Y., \& Ghazali, H. M. (2018). Selected physicochemical properties of registered clones and wild types rambutan (Nephelium lappaceum L.) fruits and their potentials in food products. Sains Malaysiana, 47(7), 1483-1490.

[3] Cheok, C. Y., Salman, H. A. K., \& Sulaiman, R. (2014a). Extraction and quantification of saponins: A review. Food Research International, 59(May), 16-40. https://doi.org/10.1016/j.foodres.2014.01.057.

[4] Desai S. D., Desai, D. G., \& Kaur, H. (2009). Saponins and their biological activities. Pharma Times, 41(3), 13-16.

[5] Faroka, R. F., Seminar, B. K., \& Muljono, P. (2011). No 主観的健康感を中心とした在宅高齢者における健康関連指標 に関する共分散構造分析Title. Pengaruh Adopsi Teknologi PHSL (Pemupukan Hara Spesifik Lokasi) Berbasis Pertanian Presisi Terhadap Pendapatan Petani Padi Di Desa Jembungan, Kabupaten Boyolali, Jawa Tengah, 11(1), 147-173.

[6] Guclu-Ustundag, Ö., \& Mazza, G. (2007). Saponins: Properties, applications, and processing. Critical Reviews in Food Science and Nutrition, 47(3), 231-258.

[7] Holmberk K. (2001). Natural surfactants. Current Opinion in Colloid \& Interface Science, 6, 148-159.

[8] Huang, H.-C., Liao, S.-C., Chang, F.-R., Kuo, Y.-H., \& Wu, Y.-C. (2003). Molluscicidal saponins from Sapindus Mukorossi, inhibitory agents of golden apple snails, Pomacea Canaliculata. Journal of Agricultural and Food Chemistry, 51(17), 49164919.

[9] Mainkar, A. R., \& Jolly, C. I. (2000). Evaluation of commercial herbal shampoos. International Journal of Cosmetic Science, 22(5), 385-391.

[10] Mousli, R., \& TAZEROUTI, A. (2007). Direct Method of Preparation of Dodecanesulfonamide Derivatives and Some Surface Properties. Journal of Surfactants and Detergents, 10, 279-285.

[11] Nkafamiya, I., Honda, J., Eneche, J., \& Haruna, M. (2018). Extraction and Evaluation of a Saponin-base Surfactant from Cissus Populnea Plant as an Emulsifying Agent. Asian Journal of Chemical Sciences, 4(1), 1-7.

[12] Mondal, M., Goswami, S., Ghosh, A., Oinam, G., Tiwari, O, N., Das, P., Gayen, K., Mandal, M, K., \& Halder, G.N. (2017). Production of Biodiesel from Microalgae through Carbon Capture: A review. 3 Biotech, 7(5), 99-101.

[12] Mondal, M., Goswami, S., Ghosh, A., Oinam, G., Tiwari, O, N., Das, P., Gayen, K., Mandal, M, K., \& Halder, G.N. (2017). Production of Biodiesel from Microalgae through Carbon Capture: A review. 3 Biotech, 7(5), 99-101.

[13] Riekkola, M.-L. (2000). ELECTROPHORESIS | Micellar Electrokinetic Chromatography. In I. D. Wilson (Ed.), Encyclopedia of Separation Science (pp. 1280-1286). Academic Press.

[14] Shahrajabian, M. H., Sun, W., Khoshkharam, M., \& Qi Cheng. (2020). Rambutan, a tropical plant with ethno-pharmaceutical properties. Agrocoencia, 54(1).

[15] Siwayanan, P., Bakar, N. A., Aziz, R., \& Chelliapan, S. (2015). Exploring Malaysian household consumers' acceptance towards eco-friendly laundry detergent powders. Asian Social Science, 11(9), 125-137.

[16] Wall, M. M. (2006). Ascorbic acid and mineral composition of longan (Dimocarpus longan), lychee (Litchi chinensis), and rambutan (Nephelium lappaceum) cultivars grown in Hawaii. Journal of Food Composition and Analysis, 19(6-7), 655-663.

[17] Williams, J. J. (2007). B.1.II - Formulation of Carpet Cleaners. In I. Johansson \& P. Somasundaran (Eds.), Handbook for Cleaning/Decontamination of Surfaces (pp. 103-123). 